\title{
Perforator Flap is Better Option for Sacral Pressure Ulcer Repair because of Fewer Complications: Comparative Study of 20 Perforator and 11 Rotation Flap Surgeries
}

\author{
Masaki Fujioka* \\ Department of Plastic and Reconstructive Surgery, National Hospital Organization Nagasaki Medical Center, Japan
}

Received: March 30, 2015; Accepted: June 30, 2015; Published: June 31, 2015

*Corresponding author: Masaki Fujioka, Department of Plastic and Reconstructive Surgery, National Hospital Organization Nagasaki Medical Center, Japan, Tel: +81 0957-52-3121; Fax: +81 0957-54-0292; E-mail: mfujioka@nagasaki-mc.com

\begin{abstract}
Extensive sacral pressure ulcers often require the use of flaps for resurfacing, including gluteal muscle flaps, and fasciocutaneous perforator or rotation flaps. However, knowledge about the most effective and suitable techniques remains limited. A retrospective cohort study was conducted in 31 patients (16men, 15 women) with Stage IV sacral pressure ulcers to assess the duration of wound healing and postsurgical complications following two types of surgical closure procedure, perforator and rotation fasciocutaneous flaps. Twenty perforator and 11 rotation flap surgeries performed in a general hospital from 2011 through 2014 were evaluated. There were no significant differences in patient demographics between the two groups. The median time to healing in patients with a perforator flap was 17 days (range,_10-58 days), and it was 34 (range, 11-80 days) in patients with a rotation flap $(P<0.05$, Wilcoxon signed rank test). Patients who underwent rotation flap surgery had a higher rate of postoperative complications, and a significantly higher rate of postsurgical seroma (9/11) compared to those who underwent perforator flap surgery $(3 / 20)(P<0.01)$. The results of this study show that the proportion of patients who develop a seroma following surgical repair of a sacral pressure is lower following perforator than rotation flap surgery. We conclude that, our small sample indicates a perforator flap technique leads to lower complication rates, but more prospective studies are needed to change recommendation and choice of operation technique.
\end{abstract}

Keywords: Pressure ulcers; Perforator flap; Rotation flap; Postsurgical complications; Sacral pressure ulcer

\section{Introduction}

Pressure ulcers classified as Stage IV (according to National Pressure Ulcer Advisory Panel staging guidelines) [1] take a long time to heal, and may cause serious infections, such as osteomyelitis and sepsis [2-5]. Thus, they usually require surgical repair using a muscle or fasciocutaneous flap (according to International Guidelines). Treatment of Pressure Ulcers: Quick Reference Guide) Gluteal fasciocutaneous flaps are commonly preferred, because they facilitate the preservation of the gluteal muscle integrity and muscle function [6]. They are also expected to provide better long-term results following the surgical reconstruction of pressure ulcers than the myocutaneous or muscle flap [7]. Traditionally, the gluteal fasciocutaneous rotation flap technique has been chosen for the reconstruction of sacral pressure ulcers.

In recent years, the development of perforator flap surgery has increased the number of potential donor sites, because this type of flap can be supplied by any cutaneous perforator and donor site morbidity can be reduced. The use of gluteal perforator flap from gluteal vessels is also spreading for the resurfacing sacral pressure ulcer. Now, we can use both perforator and rotation flaps; however, the literature is scant regarding which is the better procedure.

As a common complication a seroma is described as serous fluid collection under a skin flap or in a dead space following debridement and/or flap dissection and the marked accumulation of exudate [8]. Prolonged drainage is troublesome because it can cause wound dehiscence, lead to fistulae, and increase the risk of infection, which can significantly prolong wound healing [9].

The purpose of this retrospective study was to investigate differences in the duration of wound healing and the occurrence of postsurgical complications between perforator and rotation flaps to help determine which might be the better procedure to resurface pressure ulcers in the sacral region.

\section{Methods}

\section{Study Plan and Members}

Retrospective study:

Hospitals: Thirty-one patients with Stage IV sacral pressure ulcers underwent surgical wound resurfacing with flaps in the National Organization Nagasaki Medical Center from 2012 through 2014. A retrospective review of their records was conducted.

Ethical Considerations: The procedures were in accordance with the Ethical Standards and Internal Review Board of our institutional committee (National Hospital Organization Nagasaki Medical Center) on human experimentation in 2015 (registration number 27020). All patients signed an informed consent of this study. 
Participants: We treated all Stage IV pressure ulcers until they healed, and investigated them retrospectively. We included all patients in a consecutive sample.

Patients primary disease varied. We included all patients and no diseases were excluded in this study. Among these patients, 20 pressure ulcers were reconstructed using perforator flaps (perforator flap group, 9 men, 11 women), and 11 were reconstructed using rotation flaps (rotation flap group, 7 men, 4 women). Primary disease in perforator flap group was elderly 7 , spinal cord injury 6, cerebral infarction 4, cerebral hemorrhage 3. All patients with spinal cord injury was classified into Grade A (complete neurological injury) categories in Frankel Classification grading system and those in rotation flap group were elderly 3 , spinal cord injury 3 , cerebral infarction 3 , cerebral hemorrhage 1 (Tables 1,2). As the perforator flap surgery was newly developed technique, early 11 patients underwent conventional rotation flap resurfacing, and late 20 patients did perforator flap resurfacing during research period.

Surgical procedure: The same surgical team performed all surgeries. Patients underwent surgical debridement and wound bed preparation in advance of flap surgery. The surgical procedures are standard techniques and include the thorough cleansing and debridement of all necrotic and infectious tissues and removal of the sacral bony prominence. As fasciocutaneous flaps depend on the deep fascia, subcutaneous tissue and skin for its vascular supply, thus gluteal fasciocutaneous rotation flap could be designed freely $[10,11]$. In this study, the gluteal rotation flap was design at the first quarters to be large enough to cover the sacral defect by swinging in a wide arc. Both perforator and rotation flaps are elevated above the gluteal muscle layer [12-15]. Postoperatively, a negative pressure drain was placed under the flaps for drainage until the exudate decreased to $<10$ $\mathrm{ml} /$ day. Penicillin (or cephalosporin) and anaerobic coverage (clindamycin) were used for 3 days.
Patients were provided with a body pressure dispersion mattress (Bloom ${ }^{\circledR}$, Cape Co. Ltd., Yokosuka, Japan) for 2 weeks. Two weeks after surgery, they were provided usual bed or wheelchair pressure gradually on the flap being permitted.

Data collection and analysis: Data on patient's body weight, wound size, laboratory data including serum Albumin (Alb) and Hemoglobin $(\mathrm{Hb})$, intraoperative bleeding, and the duration of the operation and anesthesia in those who underwent sacral pressure ulcer resurfacing with perforator or rotation flaps were extracted from patient charts (Table 1). Patients' body weight, wound size, and laboratory data were examined as a pre-surgical check a few days before surgery. The exudate quantity, wound separation, flap necrosis, and development of infection were also extracted. Wound healing was determined when all sutures were removed without wound complications, such as a seroma, fistulae, infection, flap necrosis, or wound dehiscence $[16,17]$.

If these complications were noted, they were managed using drainage, re-operation, or the administration of antibiotics. In such cases, once the problems were resolved and no further treatment was required, the wound was recorded as being healed.

\section{Results}

\section{Patient demographics and health status}

Thirty-one patients with Stage IV sacral pressure ulcers were found to have undergone surgical wound resurfacing with flaps. Of these, 20 pressure ulcers were repaired using perforator flaps (perforator flap group) and 11 were covered with rotation flaps (rotation flap group). The data revealed no significant differences between the groups in the body weight, wound size, Alb, Hb, intraoperative bleeding, or duration of the surgical flap procedure $(P>0.05$, Wilcoxon signed rank test, Table 1$)$. The patients' wound size, interval between resurfacing surgery and wounds healing, and general and postsurgical wound complications in the

Table 1: Body weight, Wound Size, Laboratory Data, Bleeding, and Duration of Operation and Anesthesia in Patients Who Underwent Sacral Pressure Ulcer Resurfacing with perforator / rotation Flaps.

\begin{tabular}{|c|c|c|c|}
\hline \multicolumn{2}{|c|}{ Measurements } & \multirow{2}{*}{$\begin{array}{c}\text { Median (Range) } \\
60(18-90)\end{array}$} & \multirow{3}{*}{$\begin{array}{r}\text { Pvalue } \\
0.75\end{array}$} \\
\hline \multirow{2}{*}{ Age (years old) } & Perforator flap group & & \\
\hline & Rotation flap group & $58(37-87)$ & \\
\hline \multirow{2}{*}{ Body weight (Kg) } & Perforator flap group & $61(33-80)$ & \multirow{2}{*}{0.31} \\
\hline & Rotation flap group & $57(20-79)$ & \\
\hline \multirow{2}{*}{ Wound size $\left(\mathrm{cm}^{2}\right)$} & Perforator flap group & $49(6-140)$ & \multirow{2}{*}{0.15} \\
\hline & Rotation flap group & $42(9-80)$ & \\
\hline \multirow{2}{*}{$\operatorname{Alb}(\mathrm{g} / \mathrm{dl})$} & Perforator flap group & $2.7(1.8-4.2)$ & \multirow{2}{*}{0.08} \\
\hline & Rotation flap group & $3.3(2.9-4.2)$ & \\
\hline \multirow{2}{*}{$\mathrm{Hb}(\mathrm{g} / \mathrm{dl})$} & Perforator flap group & $9.8(6.3-14.0)$ & \multirow{2}{*}{0.08} \\
\hline & Rotation flap group & $12.2(7.6-17.6)$ & \\
\hline \multirow{2}{*}{ Intraoperative bleeding $(\mathrm{ml})$} & Perforator flap group & $50(20-345)$ & \multirow{2}{*}{0.92} \\
\hline & Rotation flap group & $72(20-220)$ & \\
\hline \multirow{2}{*}{ Operation time (minutes) } & Perforator flap group & $111(30-145)$ & \multirow{2}{*}{0.64} \\
\hline & Rotation flap group & $120(49-166)$ & \\
\hline \multirow{2}{*}{ Anesthesia time (minutes) } & Perforator flap group & $211(106-300)$ & \multirow{2}{*}{0.34} \\
\hline & Rotation flap group & $235(75-331)$ & \\
\hline
\end{tabular}


Table 2: Cases of the Sacral Pressure Ulcers Reconstruction Using Perforator Flaps.

\begin{tabular}{|c|c|c|c|c|c|c|c|c|c|}
\hline & Primary disease & $\begin{array}{l}\text { Duration to } \\
\text { heal (Days) }\end{array}$ & Complication & Seroma & $\begin{array}{l}\text { Wound } \\
\text { infection }\end{array}$ & $\begin{array}{l}\text { Partial } \\
\text { necrosis }\end{array}$ & $\begin{array}{l}\text { Wound } \\
\text { separation }\end{array}$ & $\begin{array}{l}\text { Additional } \\
\text { treatment }\end{array}$ & Relapse \\
\hline 1 & elderly & 58 & & $\circ$ & 0 & & & Free skin graft & \\
\hline 2 & elderly & 15 & & & & & & & \\
\hline 3 & $\begin{array}{c}\text { spinal cord injury/ } \\
\text { paraplegic }\end{array}$ & 17 & & & & $\circ$ & & & \\
\hline 4 & $\begin{array}{l}\text { Cerebral infarction/ } \\
\text { hemiplegic }\end{array}$ & 10 & & & & & & & \\
\hline 5 & $\begin{array}{l}\text { spinal cord injury/ } \\
\text { paraplegic }\end{array}$ & 17 & DM & & & & & & \\
\hline 6 & $\begin{array}{c}\text { cerebral infarction/ } \\
\text { hemiplegic }\end{array}$ & 10 & & & & & & & \\
\hline 7 & elderly & 10 & & & & & & & \\
\hline 8 & elderly & 30 & RA & $\circ$ & & & & Sclerotherapy & \\
\hline 9 & $\begin{array}{l}\text { spinal cord injury/ } \\
\text { paraplegic }\end{array}$ & 17 & & & & & & & \\
\hline 10 & $\begin{array}{c}\text { cerebral infarction/ } \\
\text { hemiplegic }\end{array}$ & 14 & & & & & & & \\
\hline 11 & $\begin{array}{c}\text { cerebral infarction/ } \\
\text { hemiplegic }\end{array}$ & 20 & & & & & & & \\
\hline 12 & elderly & 35 & & & & & $\circ$ & re-suture & \\
\hline 13 & elderly & 14 & & & & & & & \\
\hline 14 & $\begin{array}{c}\text { cerebral hemorrhage/ } \\
\text { hemiplegic }\end{array}$ & 50 & DM & & & $\circ$ & & Free skin graft & \\
\hline 15 & $\begin{array}{c}\text { cerebral hemorrhage/ } \\
\text { hemiplegic }\end{array}$ & 14 & & & & & & & \\
\hline 16 & $\begin{array}{c}\text { spinal cord injury/ } \\
\text { paraplegic }\end{array}$ & 16 & & & & & & & \\
\hline 17 & elderly & 44 & DM & $\circ$ & & & & Sclerotherapy & \\
\hline 18 & $\begin{array}{c}\text { cerebral hemorrhage/ } \\
\text { hemiplegic }\end{array}$ & 10 & & & & & & & \\
\hline 19 & $\begin{array}{c}\text { spinal cord injury/ } \\
\text { paraplegic }\end{array}$ & 21 & & & & & & & \\
\hline 20 & $\begin{array}{l}\text { spinal cord injury/ } \\
\text { paraplegic }\end{array}$ & 10 & & & & & & & \\
\hline
\end{tabular}

Note: DM( Diabetes Mellitus), RA(Rheumatoid Arthritis)

perforator and rotation flap groups are shown in Tables 2 and 3. Postsurgical observation was performed until patients' full mobilization was achieved. The median follow-up period was 12 (range, 4-30) months; there was one episode of recurrence 6 month after surgery in the rotation flap group. All 31 sacral pressure ulcers healed within 80 days after surgery.

\section{Complications}

Postsurgical wound complications in the perforator flap group included seroma (3), postsurgical wound infection (1), and partial flap necrosis (2). Two patients required an additional free skin graft for the treatment of a remaining wound due to infection, another two patients underwent additional sclerotherapy for the treatment of a seroma, and another one patient underwent resuture. Complications in the rotation flap group included seroma (9), postsurgical wound infection (1), partial flap necrosis (1), and dehiscence (3). One patient required additional perforator flap transfer for the treatment of a remaining wound due to dehiscence, and another patient underwent sclerotherapy to treat the seroma. Patients who underwent rotation flap surgery were significantly more likely to develop a postsurgical seroma than those who underwent perforator flap surgery $(P<0.01$, chi-square test) (Figure 1). Patients who underwent rotation flap surgery were also significantly more likely to develop postsurgical complications such as infections, flap necrosis, and dehiscence, than those who underwent perforator flap surgery $(P$ $<0.05$, chi-square test) (Figure 2).

\section{Healing}

The median healing time was 17 (range, 10-58) days in the perforator flap group and 34 (range, 11-80) days in the rotation flap group. The healing time in the perforator flap group was significantly shorter than in the rotation flap group $(P=0.04$, Wilcoxon signed rank test) (Figure 3). 
Table 3: Cases of the Sacral Pressure Ulcers Reconstruction Using Rotation Flaps.

\begin{tabular}{|c|c|c|c|c|c|c|c|c|c|c|c|c|c|}
\hline & \multicolumn{2}{|c|}{ Primary disease } & \multicolumn{2}{|c|}{$\begin{array}{l}\text { Duration to } \\
\text { heal (Days) }\end{array}$} & \multicolumn{2}{|c|}{ Complication } & Seroma & $\begin{array}{l}\text { Wound } \\
\text { infection }\end{array}$ & $\begin{array}{c}\text { Partial } \\
\text { necrosis }\end{array}$ & \multicolumn{2}{|c|}{$\begin{array}{c}\text { Wound } \\
\text { separation }\end{array}$} & $\begin{array}{l}\text { Additional } \\
\text { treatment }\end{array}$ & Relapse \\
\hline 1 & \multicolumn{2}{|l|}{ elderly } & \multicolumn{2}{|c|}{14} & \multicolumn{2}{|c|}{$\begin{array}{l}\text { Malignant } \\
\text { Lymphoma }\end{array}$} & $\circ$ & & $\circ$ & & & & \\
\hline 2 & \multicolumn{2}{|l|}{ elderly } & \multicolumn{2}{|c|}{20} & \multicolumn{2}{|c|}{$\mathrm{RA}$} & $\circ$ & & & & & & \\
\hline 3 & \multicolumn{2}{|c|}{ spinal cord injury/paraplegic } & \multicolumn{2}{|c|}{35} & \multicolumn{2}{|c|}{ RA,DM } & $\circ$ & & & & & & \\
\hline 4 & \multicolumn{2}{|c|}{ cerebral infarction/ hemiplegic } & \multicolumn{2}{|c|}{34} & & & o & & & & & & \\
\hline 5 & \multicolumn{2}{|c|}{ spinal cord injury/paraplegic } & \multicolumn{2}{|c|}{80} & & & $\circ$ & o & & & & & \\
\hline 6 & \multicolumn{2}{|c|}{ cerebral infarction/ hemiplegic } & \multicolumn{2}{|c|}{23} & & & o & & & \multicolumn{2}{|c|}{ o } & & \\
\hline 7 & \multicolumn{2}{|c|}{ elderly } & \multicolumn{2}{|c|}{49} & & & $\circ$ & & & & $\circ$ & Perfolato & \\
\hline 8 & spinal cord injury/ & raplegic & & & & & $\circ$ & & & & & Sclerothe & $\circ$ \\
\hline 9 & $\begin{array}{r}\text { cerebral hemor } \\
\text { hemipleg }\end{array}$ & age/ & & & & M & ○ & & & & ○ & & \\
\hline 10 & spinal cord injury/ & raplegic & & & & & & & & & & & \\
\hline 11 & cerebral infarction/ & miplegic & & & & & & & & & & & \\
\hline & $\begin{array}{l}\text { Duration to heal } \\
\text { (Days) }\end{array}$ & Complica & tion & Ser & & $\begin{array}{r}\text { Wour } \\
\text { infecti }\end{array}$ & & $\begin{array}{c}\text { Partial } \\
\text { necrosis }\end{array}$ & $\begin{array}{r}\text { Wound } \\
\text { separatic }\end{array}$ & & $\begin{array}{l}\text { Add } \\
\text { trea }\end{array}$ & $\begin{array}{l}\text { ditional } \\
\text { atment }\end{array}$ & Relapse \\
\hline 1 & 14 & $\begin{array}{l}\text { Malign } \\
\text { Lympho }\end{array}$ & & sen & & & & $\circ$ & & & & & \\
\hline 2 & 20 & RA & & & & & & & & & & & \\
\hline 3 & 35 & $\mathrm{RA}, \mathrm{DI}$ & & & & & & & & & & & \\
\hline 4 & 34 & & & & & & & & & & & & \\
\hline 5 & 80 & & & & & $\circ$ & & & & & & & \\
\hline 6 & 23 & & & 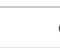 & & & & & o & & & & \\
\hline 7 & 49 & & & & & & & & $\circ$ & & Perfol & lator flap & \\
\hline 8 & 55 & & & 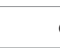 & & & & & & & Sclerc & otherapy & o \\
\hline 9 & 70 & DM & & & & & & & o & & & & \\
\hline 10 & 11 & & & & & & & & & & & & \\
\hline 11 & 12 & & & & & & & & & & & & \\
\hline
\end{tabular}

Note: DM( Diabetes Mellitus), RA(Rheumatoid Arthritis)

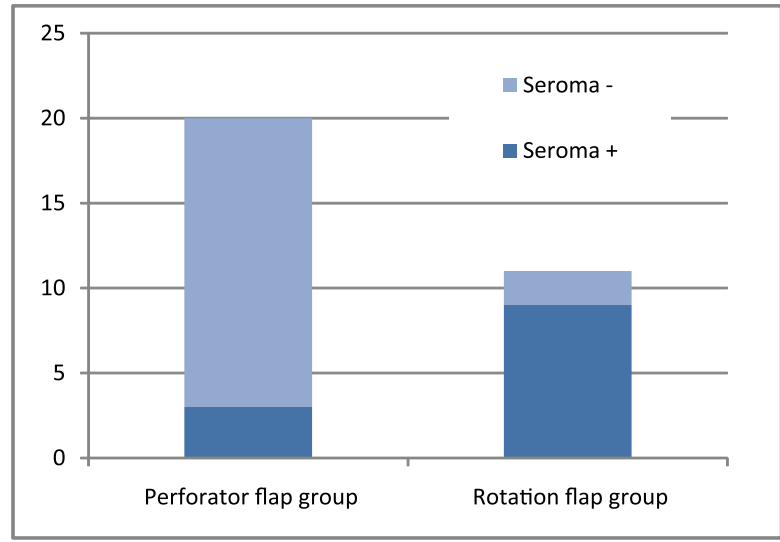

Figure 1: Differences in pressure ulcer healing time in the perforator and rotation flap groups.

\section{Discussion}

Stage IV or III sacral pressure ulcers usually require surgical treatment, and gluteal fasciocutaneous and gluteal perforatorbased flaps are currently recommended for reconstruction $[2-5,18]$. For any type of flap, the donor site requires closure, which is a common site for the development of a postoperative seroma. The current study revealed that postsurgical healing is influenced by seroma formation, which significantly prolonged the healing time [19]. Koshima I, et al., [20] reported that in eight pressure ulcers treated with gluteal perforator flaps, one fistula occurred. Lin PY, et al., [21] identified one seroma in 46

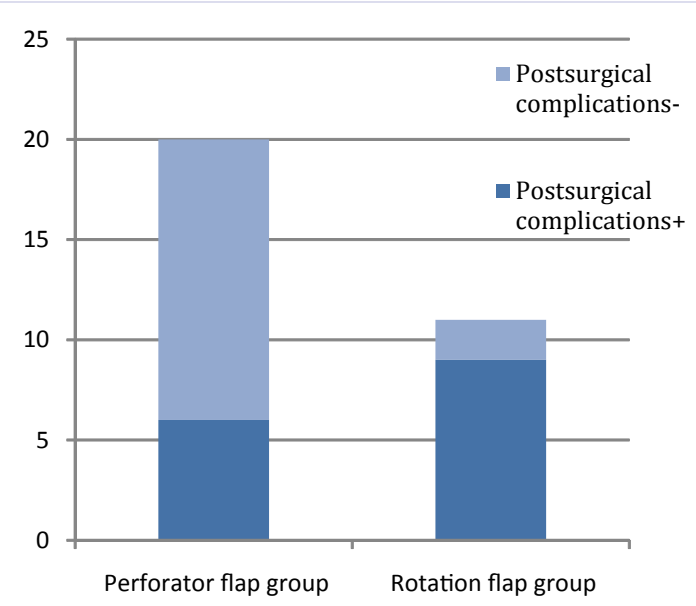

Figure 2: Development of postsurgical seroma in the perforator and rotation flap groups. 


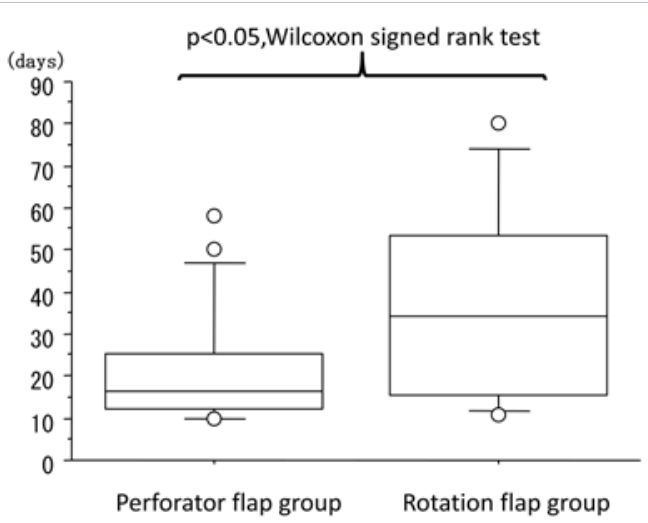

Figure 3: Development of postsurgical complications in the perforator and rotation flap groups.

gluteal perforator flaps; Xu Y, et al., [22] also noted one seroma among six flaps. Leow M, et al., [23] reported four successful gluteal perforator flap surgeries without seroma formation. These outcomes suggest that perforator flaps are less likely to lead seroma development, although the frequency of seroma formation after fasciocutaneous rotation flap use is unknown. In the current study, three out of 20 patients receiving perforator flaps and nine out of 11 receiving fasciocutaneous rotation flaps developed postsurgical seromas; higher frequency of seroma formation in our cases might due to earlier removal of suction drain or earlier mobilization of patients after surgery, however, these are same standardized procedure for both rotation and perforator flap groups, which was not biased toward this study. Fasciocutaneous rotation flap use was significantly more likely to lead to seroma formation.

The known advantages of using perforator flaps over traditional flaps include reduced bleeding, preservation of the muscle and its function, and versatility of the flap design that yields a better match to the defect [23]. To resurface a sacral round pressure ulcer with a $7-\mathrm{cm}$ diameter, the area to elevate a perforator flap is about $60 \mathrm{~cm}^{2}$, on the other hand, that for a fasciocutaneous rotation flap is approximately $120 \mathrm{~cm}^{2}$. A perforator flap requires half the area of fascial dissection compared to a fasciocutaneous rotation flap (Figures 4,5). It is considered that a larger dissection causes both more bleeding and a larger dead space, consequently, resulting in a higher rate seroma development. The postoperative development of a seroma increased the time to healing.

\section{Limitations}

The current findings may be limited by the small series of patients and retrospective study design. However, although these surgeries were performed by the same surgical group and no preconception regarding the choice of surgery was documented, one of the causes of seroma was thought to be surgical factors including rough surgical maneuvers, remaining dead space, and the extent of dissection needed to cover the wounds.

\section{Conclusion}

A retrospective study of 31 cases in which sacral ulcer repair involved either perforator or rotator flap approaches showed that the use of perforator flaps resulted in fewer complications and a faster time to healing compared to the use of rotator flap. Future research prospective and randomized controlled has to be done, to prove whether perforator is really a better option.

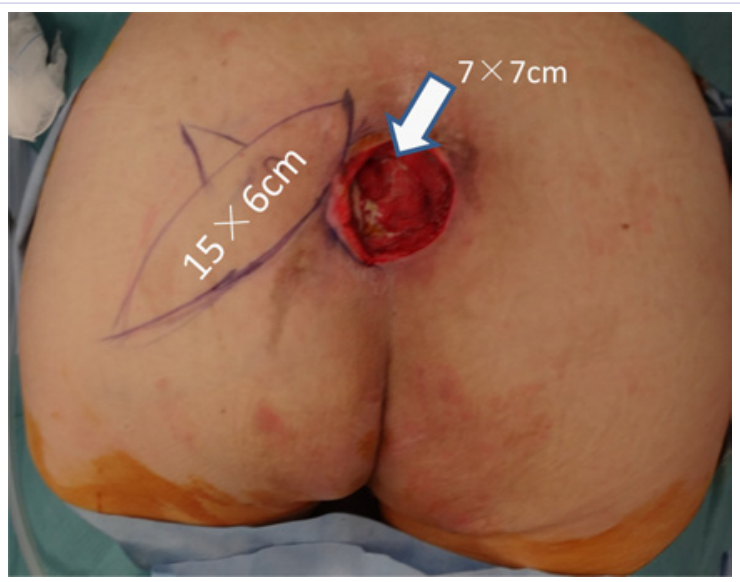

Figure 4a: The design of the perforator flap.

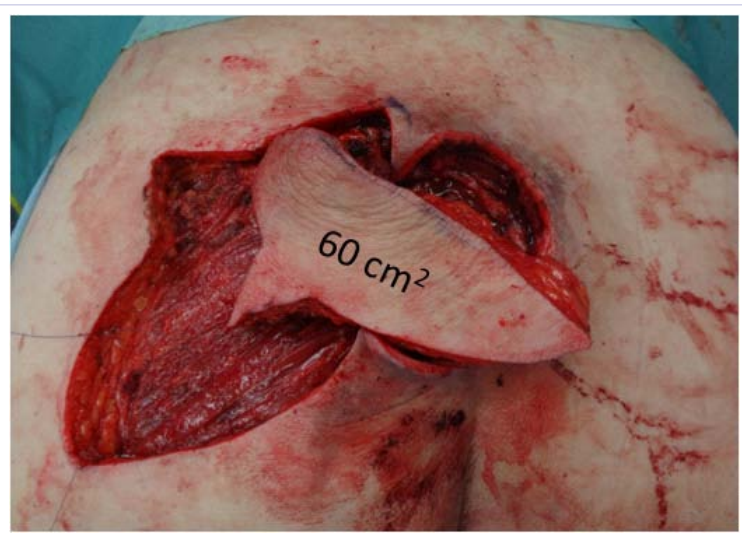

Figure 4b: The extent of dissection to elevate the perforator flap.

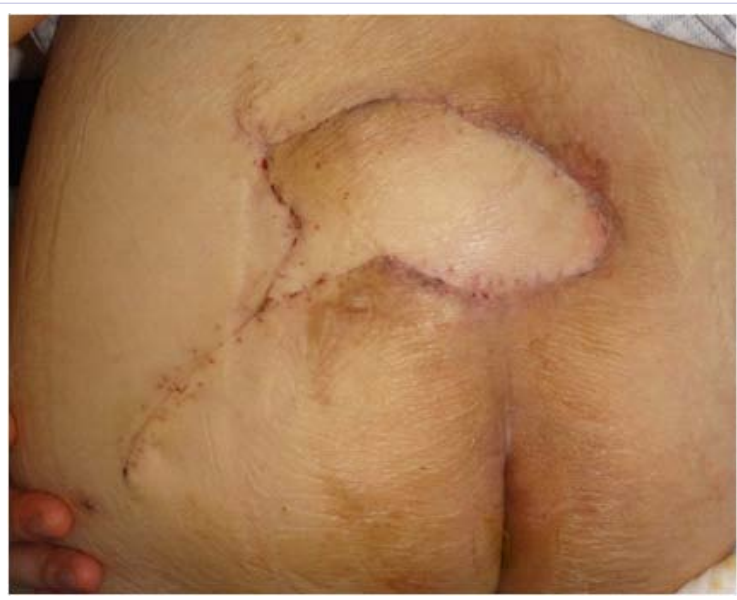

Figure 4c: The picture shows a pressure ulcer resurfaced using a perforator flap without any complications 2 weeks after surgery. 


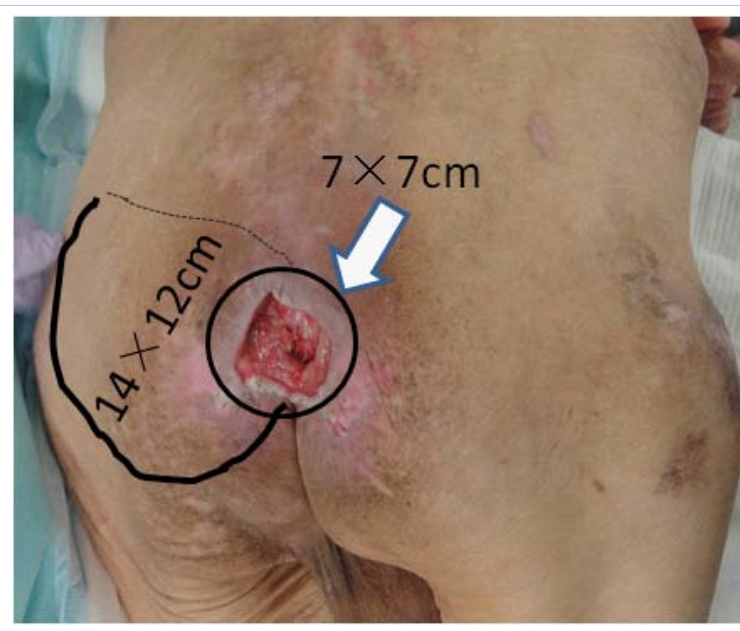

Figure 5a: The design of the rotation flap.

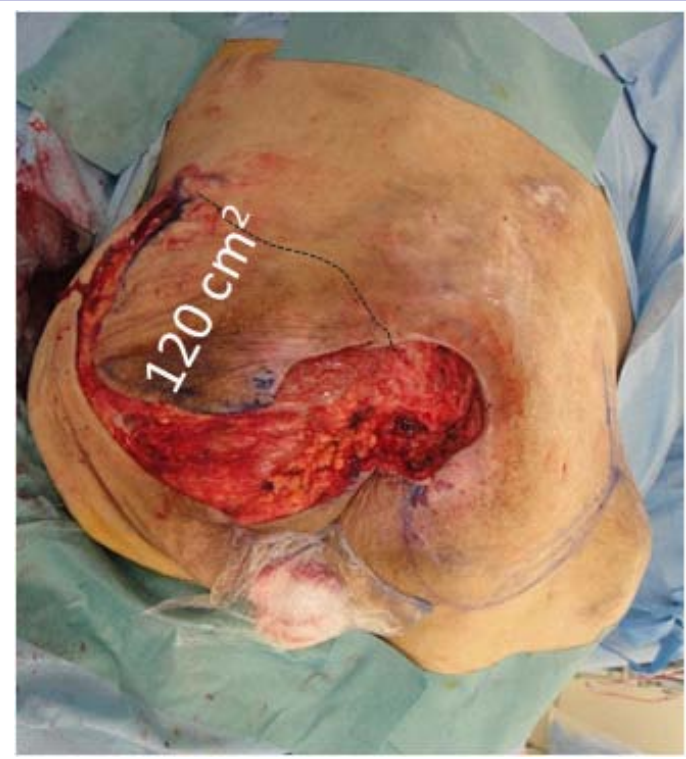

Figure 5b: The extent of dissection to elevate the rotation flap.

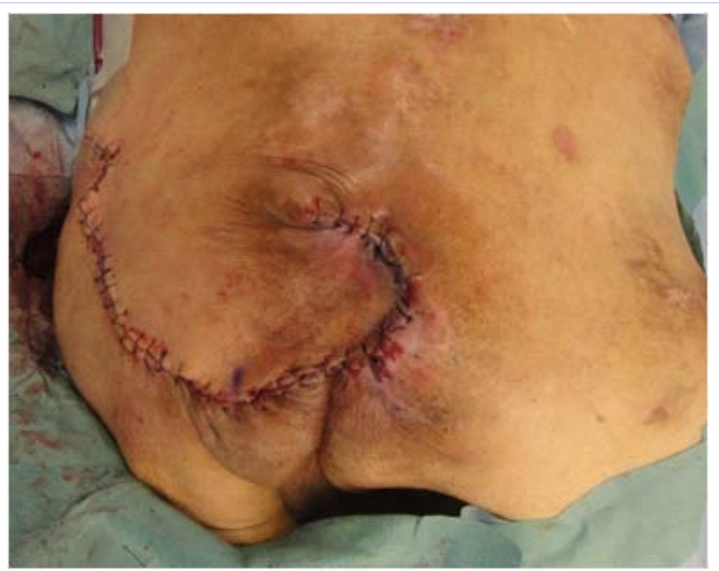

Figure 5c: The picture shows that the pressure ulcer was repaired using rotation flap.

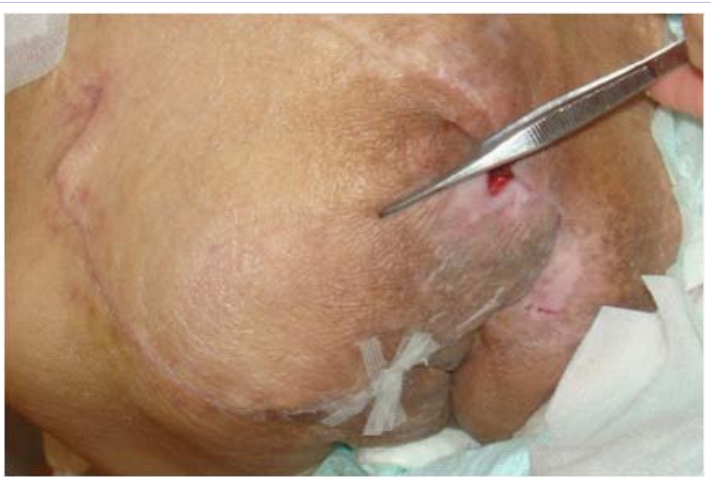

Figure 5d: The picture shows the development of a seroma and fistulae 2 weeks after surgery.

\section{Acknowledgment}

we are appreciative of the participation and agreement with this study from the patients, and helpful advice from the editors.

\section{References}

1. The National Pressure Ulcer Advisory Panel (NPUAP) serves as the authoritative voice for improved patient outcomes in pressure ulcer prevention and treatment through public policy, education and research. NPUAP Pressure Ulcer Stages/Categories.

2. Black J, Baharestani M, Cuddigan J, Dorner B, Edsberg L, Langemo D, et al. National Pressure Ulcer Advisory Panel's updated pressure ulcer staging system. Dermatol Nurs. 2007; 19(4):343-9.

3. Bluestein D, Javaheri A. Pressure ulcers: prevention, evaluation, and management. Am Fam Physician. 2008; 78(10):1186-94.

4. Livesley NJ, Chow AW. Infected pressure ulcers in elderly individuals. Clin Infect Dis. 2002; 35(11):1390-6.

5. Marriott R, Rubayi S. Successful truncated osteomyelitis treatment for chronic osteomyelitis secondary to pressure ulcers in spinal cord injury patients. Ann Plast Surg. 2008; 61(4):425-9. doi: 10.1097/ SAP.0b013e318162f257.

6. International Guideline. Treatment of Pressure Ulcers: Quick Reference Guide. European Pressure Ulcer Advisory Panel \&National Pressure Ulcer Advisory Panel 2009.

7. Stevenson TR, Pollock RA, Rohrich RJ, VanderKolk CA. The gluteus maximus musculocutaneous island flap: refinements in design and application. Plast Reconstr Surg. 1987; 79(5):761-8.

8. Bailey SH, Oni G, Guevara R, Wong C, Saint-Cyr M. Latissimus dorsi donor-site morbidity: the combination of quilting and fibrin sealant reduce length of drain placement and seroma rate. Ann Plast Surg. 2012; 68(6):555-8. doi: 10.1097/SAP.0b013e318216b65c

9. Srivastava V, Basu S, Shukla VK. Seroma formation after breast cancer surgery: what we have learned in the last two decades. J Breast Cancer. 2012; 15(4):373-80. doi: 10.4048/jbc.2012.15.4.373.

10. Diaz S, Li X, Rodríguez L, Salgado CJ. Update in the Surgical Management of Decubitus Ulcers. Anaplastology. 2013; 2(3):113. doi: 10.4172/2161-1173.1000113.

11. Levine SM, Sinno S, Levine JP, Saadeh PB. Current Thoughts for the Prevention and Treatment of Pressure Ulcers Using the Evidence to Determine Fact or Fiction. Ann Surg. 2013; 257(4):603-8. doi: 10.1097/SLA.0b013e318285516a. 
12. Ahmadzadeh R, Bergeron L, Tang M, Morris SF. The superior and inferior gluteal artery perforator flaps. Plast Reconstr Surg. 2007; 120(6):1551-6.

13. Masaki F, Shuhei Y, Riko K. A technique to avoid a dog-ear deformity on buttock using a "pigeon head" modification of the rotation flap. Wounds. 2007; 19(3):69-72.

14. Windhofer Ch, Michlits W, Gruber S, Papp Ch. Reconstruction in the buttock region using the local fasciocutaneous infragluteal (FCI) flap. J Plast Reconstr Aesthet Surg. 2010; 63(1):126-32. doi: 10.1016/j. bjps.2008.08.050.

15. Yamamoto Y, Ohura T, Shintomi Y, Sugihara T, Nohira K, Igawa H Superiority of the fasciocutaneous flap in reconstruction of sacral pressure sores. Ann Plast Surg. 1993; 30(2):116-21.

16. Käser SA, Zengaffinen R, Uhlmann M, Glaser C, Maurer CA. Primary wound closure with a Limberg flap vs. secondary wound healing after excision of a pilonidal sinus: a multicentre randomised controlled study. Int J Colorectal Dis. 2015; 30(1):97-103. doi: 10.1007/s00384014-2057-x.

17. Weaver TS, Wester JL, Gleysteen JP, Peck JJ, Wax MK. Surgical outcomes in the elderly patient after osteocutaneous free flap transfer. Laryngoscope. 2014; 124(11):2484-8. doi: 10.1002/lary.24762.
18. Yamamoto $Y$, Tsutsumida A, Murazumi M, Sugihara T. Long-term outcome of pressure sores treated with flap coverage. Plast Reconstr Surg. 1997; 100(5):1212-7.

19. Fujioka M, Hayashida K, Morooka S, Saijo H. A retrospective comparison of perforator and rotation flaps for the closure of extensive Stage IV sacral pressure ulcers. Ostomy Wound Manage. 2014; 60(4):42-8.

20. Koshima I, Moriguchi T, Soeda S, Kawata S, Ohta S, Ikeda A. The gluteal perforato-based flap for repair of sacral pressure sores. Plast Reconstr Surg. 1993; 91(4):678-83.

21.Lin PY, Kuo YR, Tsai YT. A reusable perforator-preserving gluteal artery-based rotation fasciocutaneous flap for pressure sore reconstruction. Microsurgery. 2012; 32(3):189-95. doi: 10.1002/ micr.20982

22.Xu Y, Hai H, Liang Z, Feng S, Wang C. Pedicled fasciocutaneous flap of multi-island design for large sacral defects. Clin Orthop Relat Res. 2009; 467(8):2135-41. doi: 10.1007/s11999-008-0643-3.

23. Leow M, Limm J, Lim TC. The superior gluteal artery perforator flap for the closure of sacral sores. Singapore Med J. 2004; 45(1):37-9. 